\title{
La renta de la tierra y su evolución en la mitad norte de la provincia de Ávila durante los siglos XVI y XVII
}

\author{
The land-renting price and its trends in the North area \\ of Ávila during the 16th and 17th centuries
}

\author{
NOEMÍ CUERVO FUENTE \\ Centro de Estudios Superiores "Felipe II", Aranjuez, Madrid
}

\begin{abstract}
RESUMEN
En este artículo se analiza la trayectoria de la renta de la tierra percibida por el cabildo de la Catedral de Ávila en sus fincas rústicas de la mitad septentrional de dicha provincia durante los siglos XVI y XVII. Las principales conclusiones son: 1) la tasa de la renta alcanzó

un máximo algo superior al 25 por 100 de la producción bruta a finales del decenio de 1560; 2) la renta de la tierra creció de una forma bastante moderada en los seis primeros decenios del siglo XVI, cayó abruptamente en los cuatro últimos del Quinientos y en los dos primeros tercios del Seiscientos y se recuperó de una manera incompleta en el último tercio del siglo XVII; 3) considerando la duración y

la intensidad del movimiento depresivo, el norte de Ávila constituyó uno de los territorios peninsulares en los que la crisis de la renta de la tierra alcanzó una mayor magnitud durante los decenios finales del siglo XVI y la primera mitad del XVII; y 4) en el norte de Ávila los diferenciales de renta por hectárea entre las pequeñas y grandes

parcelas se ampliaron de una manera muy notable en los años postreros del Quinientos y en la primera mitad del Seiscientos.

PALABRAS CLAVE: Renta de la tierra, Usufructo, Agricultura, Ávila, España Moderna
\end{abstract}

Códigos JEL: N53, Q12

\section{ABSTRACT}

This article covers the trend of the landrenting prices of the cereal rural lands owned by the Avila Cathedral. The study done is about the North area of the region during the $16^{\text {th }}$ and $17^{\text {th }}$ centuries. The main conclusions arose by this paper are: 1) the renting-price reached a maximum level of more than 25 per 100 at the end of the $1560-1570$; 2) the land-renting prices grew moderately during the first 60 years of the $16^{\text {th }}$ century, it fell sharply during the last 40 years of that century and the next 60 years of the $17^{\text {th }}$ century, and it almost recovered during the last part of the century; 3) taking in consideration the length and intensity of the depressive trend, the area of the North of Avila was one of the Iberian territories where the crisis was more intense from the last part of the $16^{\text {th }}$ century to the first half of the $17^{\text {th }}$ century; 4 ) the spread of landrenting prices from the small and big properties grew from the last part of the $16^{\text {th }}$ century to the first half of the $17^{\text {th }}$ century.

KEY WORDS: Land rent, Right of use, Agriculture, Ávila, Modern Spain

JEL Codes: N53, Q12 


\section{Introducción ${ }^{1}$}

$\mathrm{E}$ análisis que se efectúa en este artículo de la evolución de las rentas percibidas por el cabildo catedralicio de Ávila, por la cesión a terceros del usufructo de sus labrantíos de cereal, en los siglos XVI y XVII, requiere unas palabras previas.

Durante la Edad Moderna, las relaciones entre los propietarios que no explotaban directamente sus fincas rústicas y los colonos o arrendatarios que las trabajaban eran diversas y variables, y se reflejaban en el tipo de contrato agrario que regulaba las cesiones del usufructo del terrazgo. En la Europa del sur predominaron las fórmulas contractuales en las que la renta era una cantidad fija, tanto en las cesiones a corto plazo (en general, arrendamiento en España, affitto en Italia o fermage en Francia), como en las de muy larga duración ${ }^{2}$. En la Corona de Castilla, la más habitual era el contrato de arrendamiento ${ }^{3}$. Esa supremacía no excluía la presencia de otras figuras, como los censos enfitéuticos, perpetuos o por las vidas de varios reyes o papas, los foros ofueros, u otras con denominaciones locales específicas ${ }^{4}$. En otro tipo de contratos, la renta era una parte de la producción obtenida por los renteros (la aparcería en los países de la Corona de Aragón, el métayage en el sur y oeste de Francia o la mezzadria en la Italia septentrional y central $)^{5}$. El cabildo de la Catedral de Ávila empleó, en el período objeto de estudio en este trabajo, tres tipos de contratos agrarios, el arrendamiento, el censo enfitéutico y el censo $a_{d-v i t a m^{6}}$, si bien, el primero fue el predominante en su transcurso ${ }^{7}$.

[Fecha de recepción del original, diciembre de 2005. Versión definitiva, marzo de 2006]

1 Agradezco a los evaluadores anónimos de Investigaciones de Historia Económica todas sus observaciones y sugerencias. Por supuesto, las deficiencias y errores que aparecen en el texto son de mi exclusiva responsabilidad. También, mi sincero agradecimiento a D. Bernardino Jiménez, a D. Juan Carlos Redondo y a D. Justo García González, archiveros y director, respectivamente, del Archivo Diocesano y Catedralicio de Ávila, a quienes considero, por encima de todo, mis amigos.

2 Cancila (1978); Amalric (2003).

3 Artola (1977); García Sanz (1986), pp. 299-313; Sebastián (1999); Catalán (2000), p. 157; Marcos Martín (2000), p. 216 y ss.

4 García Sanz (1986), p. 289-313; Sebastián (1999); Marcos Martín (2000), p. 216 y ss.; Amalric (2003); González Mariscal (2005).

5 Ardit (1993), vol. 1, pp. 139-174; Marcos Martín (2000), pp. 215-229; Garrabou, Planas y Saguer (2001); Amalric (2003).

6 El censo ad-vitam era una fórmula contractual peculiar que gravitaba sobre determinadas tierras del cabildo, que sólo podían cederse de ese modo, la cual únicamente podía escriturarse con canónigos de la catedral y cuya duración abarcaba la vida del canónigo o el tiempo que aquél permanecía en el cargo. Archivo Histórico Nacional (AHN, en adelante), Clero, legajos 312, 351-355, 429, 432 y 434, y códices 380-B y 410-B.

7 En 1585, del total de los ingresos por renta de la tierra del cabildo abulense, el 43,5 por 100 procedía de arrendamientos, el 20 por 100 de censos enfitéuticos y el 36,5 por 100 de censos ad-vitam. Archivo Catedralicio de Ávila (ACAv, en adelante), Libros de Cuentas de la Mesa Capitular, 1518-1700. 
Para la agricultura castellana de los siglos modernos, la renta de la tierra era relevante por varios motivos. Primero, por el elevado porcentaje de cultivadores directos que debían satisfacerla, proporción que, además, tendió a crecer entre comienzos del siglo XVI y finales del XVIII. El Censo de 1797 recoge para Ávila 1.603 labradores propietarios, 6.565 arrendatarios y 7.724 jornaleros $^{8}$. Segundo, por la alta proporción del producto bruto obtenido que solía suponer, a la cual los campesinos debían renunciar; diversos estudios señalan que, en Castilla, la renta era la principal carga a la que estaban sometidos arrendatarios y colonos ${ }^{9}$. En las propiedades del cabildo catedralicio de Ávila, a finales del siglo XVI, los renteros debían renunciar, por término medio, a la cuarta parte de la cosecha recogida. Y tercero, por la enorme extensión de terreno que se encontraba arrendada o acensuada. En la provincia abulense, a principios del siglo XIX, de un total de 333.415 fanegas, el 11,5 por 100 era cultivado por sus propietarios, mientras que el 88,5 por 100 lo era por arrendatarios ${ }^{10}$. La renta es, por tanto, una pieza fundamental para la comprensión de las relaciones de producción y distribución del excedente agrario durante la Edad Moderna. La tierra, a través de la renta que se podía obtener de ella, se presentaba para distintos grupos económicos como una alternativa de inversión con un riesgo asociado casi siempre menor que el de otras posibilidades ${ }^{11}$.

A continuación, en el segundo epígrafe se analizan críticamente las fuentes empleadas. En el tercero, se estima la tasa de renta de la tierra en las propiedades del cabildo de la Catedral de Ávila y la trayectoria de los ingresos percibidos por esta institución a través de la cesión a terceros de casi todo su patrimonio rústico. En el cuarto, se compara la evolución de la renta en Ávila con la registrada en otras zonas de la meseta castellana y en otras áreas de España, Francia e Italia. Y en el quinto, se analiza en qué medida el tamaño de los predios influía sobre la magnitud de la detracción por unidad de superficie y sobre la evolución de la renta de la tierra.

8 En Salamanca, Soria y León, la proporción de arrendatarios superaba el 50 por 100 (Sebastián, 1990, p. 53). En Palencia, el número de labradores propietarios era de 2.277, y el de arrendatarios de 5.477, bastante más del doble (Marcos Martín, 1985, p. 41). En el conjunto de Castilla y León, también según los datos de 1797, los arrendatarios casi duplicaban a los cultivadores propietarios de la tierra que labraban (Robledo, 1984, p. 74). Sin embargo, conviene recordar que no todos los arrendatarios o jornaleros eran sólo eso, sino que las figuras mixtas abundaban.

9 Brumont (1984), pp. 30-32; Sebastián (1990), p. 61.

$10 \quad$ Robledo (1984), pp. 74.

11 "Comerciantes y demás personas relacionadas con la actividad mercantil, fabricantes, banqueros, pero también funcionarios y profesionales, no dejaron de invertir en compras de tierras" (Marcos Martín, 2000, p. 190). En épocas de expansión económica, la compra de tierras auguraba prontos beneficios, bien explotándola directamente, bien cediéndola en arrendamiento; además, era un activo adecuado para diversificar la cartera de inversión. En lapsos de recesión económica, la tierra era el principal valor refugio. Pero, aparte de los económicos, existían otros motivos: la compra de tierras permitía, "independientemente del signo de la coyuntura, 'ser propietario', vivir de las rentas, fundar en definitiva la base económica de un prestigio social que abría a los enriquecidos por el comercio o las finanzas el camino hacia la nobleza" (Marcos Martín, 2000, p. 191). 


\section{Un análisis crítico de las fuentes utilizadas}

La elección del ámbito territorial ha estado determinada, fundamentalmente, por la gran calidad de las fuentes empleadas: los libros de cuentas del cabildo catedralicio de Ávila. Como los labrantíos de pan llevar del cabildo se localizaban en la mitad norte de la provincia, los datos disponibles se circunscriben a esa zona. Cuando comencé la investigación consulté fuentes civiles y eclesiásticas. Al final opté por el análisis de la renta de la tierra a través de la documentación eclesiástica, fundamentalmente de los libros de cuentas, por varios motivos.

El primero es que, respecto a las fuentes laicas, se observa en general una mayor continuidad en las fuentes eclesiásticas, y en las capitulares en particular, dada la vocación de perennidad de estas instituciones. Como los cabildos catedralicios, además, solían poseer un importante patrimonio, estaban obligados a dedicar notables esfuerzos al control de su administración y gestión; para ello era clave el registro minucioso de los ingresos, gastos y transacciones que realizaban.

La formación del patrimonio territorial del cabildo abulense fue lenta hasta que Alfonso VIII dotó a la iglesia de Ávila, otorgándole una generosa donación que inauguró un largo período de acumulación de tierras en manos de los capitulares ${ }^{12}$. El gran peso de las donaciones en la formación del patrimonio catedralicio determinó que sus propiedades, sobre todo las de carácter rústico, se encontraran diseminadas por toda la provincia, pero también en espacios hoy pertenecientes a Madrid, Salamanca, Segovia y Valladolid. La localización de las propiedades catedralicias estuvo estrechamente ligada a las características geográficas de las diferentes comarcas abulenses y al avance del proceso repoblador. La rápida ocupación del norte y del centro de la provincia determinó que el patrimonio rústico del cabildo se ubicase principalmente en la mitad septentrional de aquélla; el lento asentamiento de población en la mitad meridional de la misma dificultó la ubicación de propiedades catedralicias en esa zona ${ }^{13}$. La dispersión de los predios obligaba a los capitulares a llevar un minucioso seguimiento de sus heredades y de las características de las cesiones a terceros de su aprovechamiento. Los libros de cuentas, los apeos, y las escrituras de los contratos agrarios eran herramientas fundamentales para mantener sin merma el patrimonio capitular, y para administrarlo y gestionarlo de manera adecuada.

El segundo motivo, consecuente con el anterior, ha sido la riqueza de la información registrada en la documentación citada. Los libros de cuentas recogen todos los ingresos (o cargos) obtenidos por los capitulares, resultantes de la gestión y adminis-

\footnotetext{
12 "La etapa fundacional del dominio es anterior a la donación regia, pero [...] es la primera prueba por escrito de una adquisición catedralicia" (Barrios, 1983, p. 274).

13 Llopis y Cuervo (2003).
} 
tración del patrimonio capitular o percibidos por otros conceptos. Destacan, al efecto, dos rúbricas: las rentas territoriales y los derechos decimales. En los libros de cuentas también se consignan todos los gastos (o descargos) realizados en el desarrollo de la actividad del cabildo. Los libros son anuales y los ejercicios contables se iniciaban en octubre $^{14}$. Cada libro se divide en dos mitades. En la primera se registran todas las transacciones económicas realizadas en dinero y en la segunda todas las efectuadas en especie. A su vez, cada una de ellas se dividía en dos partes, anotándose los ingresos en la primera y los gastos en la segunda. Todas estas grandes rúbricas se subdividían en epígrafes de acuerdo a la naturaleza de las distintas operaciones que registraban. En lo que concierne a los ingresos por rentas, en cada una de las partidas se indica: la localidad donde radicaba la heredad; el tipo de contrato mediante el cual se cedía el usufructo; el nombre del arrendatario o censatario, si era individual, y si era colectivo, generalmente el de todos los renteros; la fecha de firma, la de inicio y la duración de la cesión si era un arrendamiento; si se trataba de un censo, el lugar del archivo donde se guardaba la escritura y, a veces, la fecha de suscripción; el nombre del anterior rentero; la renta o el canon que se debía abonar y el que se ingresaba; y en algunos casos, los menos, el nombre y la extensión de la heredad.

El tercer motivo ha sido la uniformidad con la que se recoge la información en los libros de cuentas durante la Edad Moderna, lo que posibilita la elaboración de series homogéneas de renta de la tierra en el largo plazo. La estructura de los libros se mantuvo prácticamente inalterada durante el período analizado. Sólo se produjo un cambio, en 1584: antes de esa fecha se agrupaban bajo un único epígrafe todos los ingresos en especie por rentas, distinguiéndose a partir de la misma los procedentes de arrendamientos de los que provenían de censos enfitéuticos y/o de censos ad-vitam.

Y el cuarto es el grado de fiabilidad que ofrece la información recogida en los citados libros de cuentas. El responsable de su redacción y conservación era el mayordomo, pero los encargados de la gestión y administración del patrimonio eran los capitulares reunidos en cabildo, es decir, los partícipes en los resultados de la explotación del patrimonio ${ }^{15}$. Al final de cada una de las dos mitades de los libros de cuentas, tanto de la de dinero como de la de grano, y una vez descontados los gastos de los ingresos, se consignaba el reparto del monto restante entre los capitulares, en porcentajes distintos según el cargo que ocupaba cada uno. Al final del año contable, una vez efectuado el reparto, las cuentas debían ser aprobadas en cabildo y sancionadas con las firmas del deán, del mayordomo y de dos canónigos más.

14 El año al que se refiere cada libro de cuentas es el del año en que termina el período contable.

15 Los canónigos se reunían en cabildo todos los miércoles y viernes para tratar temas económicos. Entre otros asuntos, decidían sobre la idoneidad de la renovación de un contrato de arrendamiento y sobre la cesión de un determinado usufructo a un rentero que lo hubiera solicitado. El contenido de tales reuniones se recoge en ACAv, Actas Capitulares del Cabildo. 
El alto grado de dispersión territorial y el elevado número de propiedades que integraba el patrimonio rústico de la Catedral de Ávila evita los problemas de representatividad que pudiesen plantearse en lo que atañe a la geografía de las fincas y al tamaño de las mismas ${ }^{16}$. No obstante, aunque la evolución de la renta de las propiedades del cabildo no debió de ser radicalmente distinta de la registrada por la de las fincas de otras instituciones eclesiásticas o la de las pertenecientes a laicos, no puede pasarse por alto que la forma de gestión de aquéllas estaba condicionada por el singular papel que el cabildo y sus miembros desempeñaban en la sociedad abulense. Por tanto, no se deben descartar diferencias entre la gestión del patrimonio del cabildo y la de otros, propios de otras instituciones religiosas o de laicos. Aparte de lo anterior, también ha de reconocerse que las fuentes catedralicias suelen silenciar los conflictos sociales habidos en torno a la renta de la tierra o, en el mejor de los casos, únicamente aportan la visión de una de las partes ${ }^{17}$.

\section{La reconstrucción de la trayectoria de la renta de la tierra en Ávila}

El cabildo de la Catedral de Ávila era una de las mayores instituciones económicas de la provincia. Fue durante el siglo XV cuando aquél se consolidó como corporación religiosa, económica y con poder independiente del obispo. La organización del cabildo catedralicio, de sus funciones, del número de sus miembros y de las obligaciones de éstos se regulaba a través de las constituciones sinodales ${ }^{18}$.

Las anotaciones efectuadas por el mayordomo en los libros de cuentas permiten apreciar que los ingresos del cabildo solían ser muy superiores a los gastos, y que se percibían en dinero y en especie, en este caso principalmente en grano (véase el Cuadro 1). La participación en los derechos decimales representaba más del 70 por 100 de los ingresos capitulares ${ }^{19}$. Durante los siglos XVI y XVII, el cabildo arrendó los diezmos

16 A mediados del siglo XVIII, en una muestra formada por 24 lugares de la mitad septentrional de la provincia de Ávila, el 11,5 por 100 de las tierras de sembradura estaba en manos de la catedral, aunque dicha proporción variaba según la clase de aquéllas, siendo del 7,6 por 100 de las de primera calidad, del 12,4 por 100 de las de segunda y del 12,0 por 100 de las de tercera. Archivo Histórico Provincial de Ávila (AHPAv, en adelante), Respuestas Particulares del Catastro de Ensenada de Albornos, Belchos, Berrocalejo, Castilblanco, La Colilla, Constanzana, Chaerrero, Flores de Ávila, Fontiveros, Fuente el Sauz, Gemerrendura, Gotarrendura, Gutierremuñoz, La Hija de Dios, Migaleles, Mingorría, Muñochás del Valleamblés, Muñogrande, Muñopepe, Muñosancho, Pajares, Palacios de Goda, Papatrigo, El Parral, Pasarilla del Rebollar, Riocabado, Salobral, Sanchorreja, Santo Domingo de las Posadas, Sotalvo, Tornadizos de Arévalo, Vicolozano, Villamayor y Los Yezgos.

17 En cuanto a las zamoranas, Álvarez Vázquez (1987), pp. 29-31.

18 García y García (1993). Sobre la organización de las catedrales de Ávila, Palencia y Burgos (ésta en la Edad Media) véanse, respectivamente, López Arévalo (1966), Cabeza (1997) y Casado (1979). 


\section{CUADRO 1}

CONTRIBUCIÓN MEDIA DE LAS DISTINTAS RÚBRICAS A LOS INGRESOS DEL CABILDO, 1500-1700

(porcentajes)

\begin{tabular}{|c|c|c|}
\hline & Rúbricas & $\begin{array}{l}\text { Porcentajes sobre } \\
\text { ingresos totales }\end{array}$ \\
\hline \multirow{4}{*}{ Ingresos totales } & Ingresos en metálico & 69,03 \\
\hline & Ingresos en especie & 30,43 \\
\hline & Ingresos en gallinas & 0,54 \\
\hline & Rúbricas & $\begin{array}{l}\text { Porcentajes sobre } \\
\text { ingresos en metálico }\end{array}$ \\
\hline \multirow{5}{*}{ Ingresos en metálico } & Rentas & 7,23 \\
\hline & Diezmos arrendados & 84,19 \\
\hline & Veintenas & 3,80 \\
\hline & Otros ingresos en metálico & 4,78 \\
\hline & Rúbricas & $\begin{array}{l}\text { Porcentajes sobre } \\
\text { ingresos en grano }\end{array}$ \\
\hline \multirow{4}{*}{ Ingresos en grano } & Rentas & 61,13 \\
\hline & Diezmos percibidos directamente & 16,93 \\
\hline & Diezmos arrendados en especie & 21,11 \\
\hline & Ingresos extraordinarios & 0,83 \\
\hline
\end{tabular}

en pública subasta en la mayoría de los lugares de la diócesis donde tenía derecho a percibirlos a cambio de una cantidad estipulada en dinero, salvo en la ciudad de Ávila, donde ésta se fijaba en grano. Sólo administró directamente sus derechos decimales en algunas de las cillas del Campo de Pajares ${ }^{20}$.

Las rentas que el cabildo obtenía por la cesión del usufructo de sus fincas, tanto rústicas como urbanas, contribuían casi en un 24 por 100 al montante total de sus ingresos. Éste se completaba con otras rentas, como entradas de beneficiados,

ACAv, Libros de Cuentas de la Mesa Capitular, 1518-1700. Los precios que me han permitido calcular el valor monetario de los ingresos en especie y deflactar las series provienen de la siguiente documentación: ACAv, Libros de Fábrica de la Catedral de Ávila, 1518-1700; Archivo Diocesano de Ávila (ADAv, en adelante), Libros de Fábrica de la parroquia de San Pedro de la ciudad de Ávila, libros 43-46, y Libros de Fábrica de la parroquia de San Nicolás de la ciudad de Ávila, libros 14-17. 
expensas de prebendados, veintenas arrendadas, juros, censos al quitar, subsidios e ingresos extraordinarios, que suponían en torno al 6 por 100 del total ingresado.

En el período considerado, más del 60 por 100 de los ingresos percibidos en grano tenía su origen en el cobro de rentas de heredades rústicas, mientras que los diezmos representaban un 38 por 100 (véase el Cuadro 1). Ello demuestra que tales rentas constituían una de las principales fuentes de ingreso del cabildo catedralicio. Su gestión no era una cuestión nimia para los capitulares abulenses, y así quedó reflejado en su interés por la conservación de los documentos relativos a aquélla.

La renta de la tierra tampoco era una cuestión baladí para los campesinos que tenían que abonarla. Varios autores han estimado, para diversas zonas de España, tasas de renta que suponen en torno al 30 por 100 de la producción cerealista bruta en el último cuarto del siglo XVI, cuando en muchos lugares la renta de la tierra alcanzó los valores máximos del Quinientos e, incluso, del Antiguo Régimen. En el decenio de 1590, en la Tierra de Santiago, la tasa de la renta se situaba en torno al 32 por 100 de la producción, y en la Tierra de Salamanca, cerca del 28,3 por 100; hacia 1575, en Castilla la Nueva era del 27,8 por 10021. En el Oriente leonés, en 1588-1593, equivalía al 30,5 por 100 del producto bruto anual ${ }^{22}$. En la Rioja, entre 1536 y 1563, la tasa de renta promedio representaba entre el 25 y el 30 por 100 de la cosecha obtenida en un año común ${ }^{23}$. En La Bureba (Burgos), el porcentaje ascendía al 30 por 100 e, incluso, al 37,5 por $100^{24}$. Por su parte, una proporción también situada en torno a un tercio de la cosecha bruta es la que implicaba la renta, en la región de París, en la segunda mitad del siglo XVII, cuando alcanzó su valor máximo ${ }^{25}$.

En el siglo XVI, en las propiedades que el cabildo abulense poseía en 31 lugares de la mitad norte de la provincia, según mi estimación, la renta de la tierra osciló entre un 27,0 y un 33,5 por 100 de la producción bruta de cereal obtenida ${ }^{26}$; el último porcentaje citado se alcanzó en 1559, fecha en la que los ingresos por renta de la tierra del cabildo registraron el máximo del período analizado. Según cálculos análogos, en el Seiscientos el referido porcentaje fluctuó entre un 15,0 y un 21,0 por 100.

En los predios rústicos que el cabildo catedralicio poseía en ocho lugares, según la información recogida en los libros de cuentas del año 1530, la tasa de renta por

\footnotetext{
21 Marcos Martín (2000), pp. 425-426.

22 Sebastián (1990), p. 61.

23 Brumont (1984), pp. 31-32.

24 Brumont (1984), pp. 109-110.

25 Le Roy Ladurie y Morineau (1977), p. 522.

26 Para calcular las tasas de renta, a partir de la muestra citada, he utilizado la información que proporcionan los Libros de Cuentas de la Mesa Capitular y el Catastro de Ensenada, tanto las Respuestas Generales como las Respuestas Particulares. He empleado los primeros para identificar las heredades del cabildo y conocer
} 
unidad de superficie era de 1,21 hectolitros de grano por hectárea (ese valor oscilaba entre 0,2 en las tierras del lugar de Las Berlanas y 1,5 en las heredades de Hernansancho $)^{27}$. ¿Cuál era el peso de esa renta en la producción campesina obtenida en las tierras arrendadas? En los pueblos de la muestra empleada, en 1530, el tamaño medio de las propiedades arrendadas era de 13 hectáreas ${ }^{28}$. Las Respuestas Particulares del Catastro indican que esas tierras se cultivaban según el sistema de año y vez, y de las Respuestas Generales se obtienen para la muestra considerada, a mediados del siglo XVIII, los rendimientos medios que se recogen en el Cuadro $3^{29}$.

la renta que generaban; y a partir de los diezmos cobrados en especie en el Campo de Pajares, he establecido la proporción que se cosechaba de cada cereal y como varió ésta durante el período analizado. El Catastro de la Ensenada lo he usado para averiguar el resto de la información necesaria para estimar las tasas. Como desconozco la extensión de muchos de los predios del cabildo en el siglo XVI, he empleado la que se recoge en las Respuestas Particulares del Catastro para mediados del XVIII. Aunque la hipótesis de que la superficie de tales predios se mantuvo invariable durante doscientos años pueda suponer un sesgo al alza de las tasas calculadas, ese exceso se reduce, al menos para el siglo XVI, al aplicar los rendimientos de mediados del XVIII al cálculo de la producción cerealista teórica en esas tierras. Si se considera, primero, que la densidad demográfica en el siglo XVI fue superior a la del XVIII (véase el Cuadro 2) y, segundo, que, como en otras zonas del interior castellano, no parece que se produjeran cambios técnicos significativos en la agricultura abulense en el período analizado, es probable que los rendimientos aplicados sean superiores a los reales de entonces. Por ese motivo, no se puede descartar que, por el lado de los rendimientos, las tasas de renta calculadas en el siglo XVI estén sesgadas a la baja. Considerando la extensión de los predios, los rendimientos por unidad de superficie según la calidad de cada tierra y los sistemas de cultivo que indica el Catastro en cada uno de los lugares de la muestra, he calculado un volumen de producción de cereal teórico en esas tierras en diferentes años. Como la cantidad de tierra dedicada al cultivo de cada cereal hubo de variar en el tiempo, he distribuido la superficie dedicada a cada cultivo considerando, tanto la información proporcionada por el Catastro, como las cantidades efectivamente cosechadas de cada uno en el Campo de Pajares. Para determinar la cantidad de tierra sembrada de cada cereal, he calculado el porcentaje que representaba cada uno, en valor medio de 9 años, sobre el total de grano cosechado en el Campo de Pajares; considerando esos porcentajes y los rendimientos obtenidos del Catastro, he estimado la superficie destinada al cultivo de cada cereal. La muestra la forman los lugares de Albornos, Belchos, Belmonte, Brieva, Cardillejo, Castilblanco, La Colilla, Crespos, Chaerrero, Chamartín, Flores de Ávila, Fontiveros, Fuente el Sauz, Gotarrendura, Helechosa, Hernansancho, La Hija de Dios, Migaleles, Muñogrande, Muñopepe, Muñosancho, Pajares, El Parral, Pasarilla del Rebollar, Riocabado, Sanchorreja, Sotalvo, Tornadizos de Arévalo, Vicolozano, Villamayor y Los Yezgos.

La muestra, en este caso, está formada por las fincas situadas en Las Berlanas, Cantiveros, La Colilla, Collado de Contreras, Hernansancho, Las Olmedillas, Riocabado y Tornadizos de Arévalo, implicando un 4 por 100 del total de la superficie de esos lugares. En Las Berlanas, la catedral poseía 36 hectáreas de sembradura, el 2,5 por 100 de la superficie del término; en Hernansancho, donde, según el Catastro de Ensenada, el cabildo era el mayor hacendado, poseía 280 hectáreas, el 14,3 por 100. ACAv, Libros de Cuentas de la Mesa Capitular, 1530.

29 Dado que la densidad demográfica era mayor en 1528 que en 1752 (véase el Cuadro 2), es probable que los rendimientos aplicados fuesen superiores a los de 1530; así no se puede descartar que las tasas calculadas en 1530 estén sesgadas a la baja. Pese a no disponer de información fiable sobre el número de habitantes de la zona durante el Seiscientos, es probable que, teniendo en cuenta la trayectoria de los bautismos y del volumen de población a mediados del siglo XVIII, la densidad demográfica durante el XVII fuese sensiblemente inferior a la del Setecientos. Es decir, en este caso, la tasa de renta puede que fuese inferior a la calculada. Para la evolución de los bautismos, Llopis y Cuervo (2004). 
CUADRO 2

DENSIDAD DEMOGRÁFICA DE CINCO COMARCAS ABULENSES EN 1528, 1591 Y $1752^{30}$

(habitantes por kilómetro cuadrado)

\begin{tabular}{lcccc}
\hline Comarcas agrarias & $\begin{array}{c}\text { Superficie } \\
\mathbf{K m}^{\mathbf{2}}\end{array}$ & $\begin{array}{c}\mathbf{1 5 2 8} \\
\mathbf{H a b} / \mathbf{K m}^{\mathbf{2}}\end{array}$ & $\begin{array}{c}\mathbf{1 5 9 1} \\
\mathbf{H a b} / \mathbf{K m}^{\mathbf{2}}\end{array}$ & $\begin{array}{c}\mathbf{1 7 5 2} \\
\mathbf{H a b} / \mathbf{K m}^{\mathbf{2}}\end{array}$ \\
\hline Tierra de Arévalo & 691,88 & 20,78 & 21,69 & 16,63 \\
Campo de Pajares & 396,21 & 13,83 & 21,04 & 19,76 \\
Moraña Baja & 531,47 & 20,57 & 23,74 & 13,12 \\
La Moraña & $1.619,56$ & 19,01 & 22,20 & 16,24 \\
Valleamblés & $2.235,09$ & 13,52 & 17,38 & 10,32 \\
\hline
\end{tabular}

Fuentes: Archivo General de Simancas (AGS, en adelante), Vecindario de 1528; Expedientes de Hacienda, legajo 768; INE (1984), y Domínguez Ortiz, Camarero y Campos (1991).

En el Campo de Pajares, la cosecha media de cereales en el período 1527-1553 estaba formada en un 47 por 100 por trigo, en un 31 por 100 por cebada y en un 22 por 100 por centeno; en cuanto a las cantidades pagadas por el usufructo de las tierras, el trigo suponía el 51 por 100, la cebada el 48 por 100 y el centeno el 1 por $100^{31}$. Cabe deducir de ello que, hacia 1530, la producción teórica de cereal obtenida en una propiedad arrendada tipo de 13 hectáreas era de 45,9 quintales métricos. Si esta hipótesis fuese acertada, la renta absorbería el 24,5 por 100 del producto bruto, un 36 por 100 más que la simiente, que suponía un 18 por 100 de aquél. En 1670, la tasa de la renta por unidad de superficie en los mismos predios era de 0,3 hectolitros por hectárea, oscilando entre un mínimo de 0,2 y un máximo de $0,7^{32}$. Lógicamente, la evolución de la tasa de la renta fue bastante similar a la de la propia renta de la tierra ${ }^{33}$.

30 Para calcular la densidad demográfica he utilizado el coeficiente 3,66 habitantes/vecino, que es el que se infiere de las cifras del Censo y del Vecindario de la Ensenada (Carasa, 1993). El método de estimación de los datos ausentes se describe en Llopis y Cuervo (2004). Sobre los problemas de los vecindarios y censos de población en la provincia abulense, véanse Llopis y Cuervo (2003) y (2004).

31 La unidad de medida utilizada por el cabildo para el arqueo de grano era la fanega de Ávila. He expresado ésta en peso mediante los coeficientes calculados por Ángel García Sanz: una fanega de trigo 44 kilogramos, una de centeno, 40,68, y una de cebada, 35,75 (García Sanz, 1985, p. 211).

32 Estas tasas de renta por unidad de superficie son inferiores a las calculadas por Postel-Vinay para la villa francesa de Vierzay: 2 hectolitros por hectárea en 1511, 2,5 en 1569 y 3 en 1646; con los altos rendimientos vigentes en la zona, esas tasas suponían un porcentaje de la cosecha bruta menor que en Ávila: un 13, un 16 y un 20 por 100, respectivamente (citado en Le Roy Ladurie y Morineau, 1977, pp. 521-522). En el señorío de Allonnes, en el Pays de la Loire, la tasa citada alcanzó su valor mínimo, 1,33 hectolitros por hectárea, entre 1596 y 1599, y registró el máximo, 2,46 hectolitros por hectárea, en 1684 (Constant, 1978). En Sicilia, por término medio, las tasas estimadas resultan menores que las abulenses; la máxima, 0,62 hectolitros por hectárea, se obtuvo en el decenio de 1690 (Cancila, 1978).

33 Siempre en el supuesto de que no se produjeran cambios significativos en la productividad agraria, en los rendimientos, en los sistemas de cultivo y en las técnicas aplicadas. Incluso aunque fuese así, no habría coincidencia plena ya que, en diversos momentos, algunas heredades quedaron sin arrendar. 


\section{CUADRO 3}

RENDIMIENTOS MEDIOS DE LOS CEREALES EN OCHO LUGARES DEL NORTE DE ÁVILA A MEDIADOS DEL SIGLO XVIII

(quintales métricos por hectárea)

\begin{tabular}{|c|c|c|c|c|c|c|c|c|c|c|c|}
\hline \multicolumn{4}{|c|}{ Trigo } & \multicolumn{4}{|c|}{ Cebada } & \multicolumn{4}{|c|}{ Centeno } \\
\hline Semilla & $r$ & $\mathbf{R}$ & $\mathbf{R}^{\prime}$ & Semilla & $\mathbf{r}$ & $\mathbf{R}$ & $\mathbf{R}^{\prime}$ & Semilla & $r$ & $\mathbf{R}$ & $\mathbf{R}^{\prime}$ \\
\hline 1,02 & 5,28 & 5,39 & 2,69 & 2,17 & 5,50 & 11,94 & 5,97 & 0,61 & 6,39 & 3,90 & 1,95 \\
\hline
\end{tabular}

r: rendimiento medio por unidad de semilla sembrada, ponderado por las extensiones y calidades de las tierras.

$\mathrm{R}$ : rendimiento medio por unidad de superficie sembrada cada año.

R': rendimiento medio por unidad de superficie cultivada en régimen de año y vez.

Fuentes: Respuestas Generales del Catastro de Ensenada de los lugares citados en la nota 26.

Queda, pues, de manifiesto que la renta solía constituir el desembolso más elevado al que debía hacer frente el campesino arrendatario, especialmente en el caso de que sólo cultivase tierras ajenas. Y, por ello, la renta de la tierra podía llegar a ser el elemento determinante de la viabilidad de la unidad de producción agraria.

El Gráfico 1 recoge la evolución de las cantidades de grano que los campesinos pagaban en concepto de renta al cabildo catedralicio de Ávila por cultivar las tierras que éste poseía en la mitad septentrional de la provincia. La serie se refiere a la renta de la tierra percibida por la cesión del usufructo de las mismas heredades durante todo el período analizado, formando parte de la misma las rentas de los predios que aparecen en los libros de cuentas del cabildo en todos y cada uno de los años situados entre 1517 y $1700^{34}$. De modo que el Gráfico 1, haciendo el supuesto de que el tamaño de las heredades no varió durante los casi doscientos años estudiados, permitiría realizar una aproximación a la evolución de la renta de la tierra por unidad de superficie pagada por los predios de "pan llevar" del cabildo catedralicio abulense ${ }^{35}$.

En la evolución de la renta pueden distinguirse tres etapas. La primera, que abarcaría la primera mitad del siglo XVI y concluiría en 1558/59, se caracterizó por el aumento de las rentas del cabildo, del orden del 14 por 100 entre 1518/19 y

34 La serie incluye una muestra de 182 heredades de las cuales, en 1600, el 53,9 por 100 estaban arrendadas, el 37,9 por 100 acensuadas y el 8,2 por 100, cedidas mediante censos ad-vitam.

35 Los libros de cuentas de la mesa capitular señalan que el tamaño de algunas heredades si cambió en dicho lapso; la magnitud del cambio, sin embargo, se situó en torno a media obrada ( 0,2 hectáreas). 


\section{GRÁFICO 1}

RENTAS EN GRANO OBTENIDAS DE 182 HEREDADES DEL CABILDO DE ÁVILA, 1517-1700

(números índice, base 100 = promedio 1578-1588)

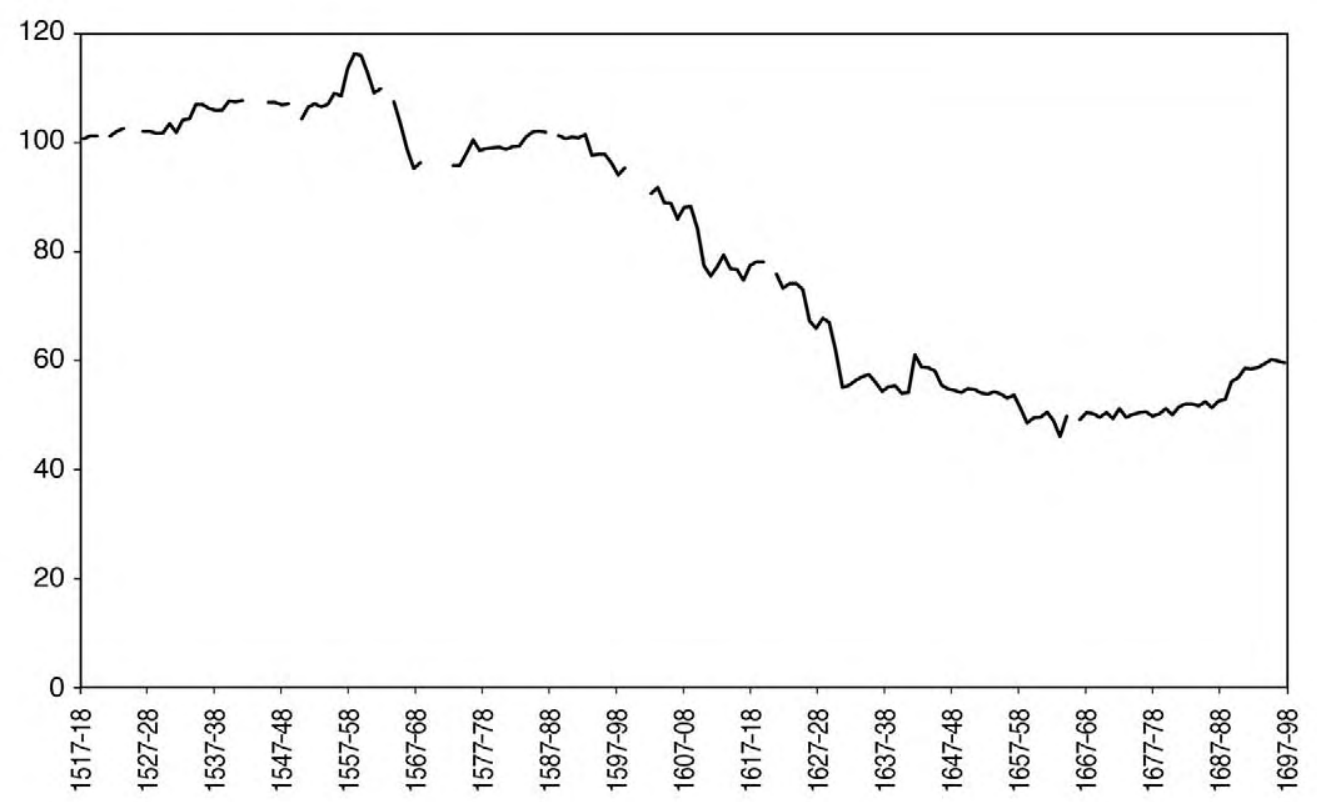

Fuentes: ACAv, Libros de Cuentas de la Mesa Capitular, 1518-1700.

1558/59 (véase el Cuadro 4). La segunda se inició hacia 1560, duró algo más de un siglo y se singularizó por la persistente caída de aquéllas, que tocó fondo en 1665/66; en este lapso, el descenso fue del 58 por 100. Y en la tercera, que incluye el último tercio del siglo XVII, aparecieron los primeros signos de recuperación: de 1665/66 a 1698/99 las rentas crecieron un 24 por 100. Conviene examinar en detalle las tres, diferenciando en la segunda distintas subetapas con la ayuda del Gráfico 1 y del Cuadro 4.

1) Entre 1518/19 y 1558/59 la renta creció moderadamente, a un ritmo anual del 0,33 por 100, quizá porque, como ocurrió en otras zonas de la submeseta norte, ya había aumentado intensamente durante la segunda mitad del siglo $\mathrm{XV}^{36}$. Tampoco

36 En Burgos, la renta de varias heredades de la catedral aumentó un 33,8 por 100 en la segunda mitad del Cuatrocientos (Casado, 1979, pp. 68 y ss.) En León, la de cuatro haciendas del monasterio de Sandoval se incrementó un 42 por 100 entre 1479-1483 y 1510-1519 (Sebastián, 1992, p. 780). 


\section{CUADRO 4}

RENTAS EN GRANO OBTENIDAS DE 182 HEREDADES DEL CABILDO DE ÁVILA, 1517-1700

(promedios anuales por trienio, kilogramos de cereal)

\begin{tabular}{cccc}
\hline Años $^{*}$ & Renta promedio & Índices & Tasa de crecimiento (\%) \\
\hline $\mathbf{1 5 1 8 / 1 9}$ & $324.582,6$ & 100,0 & \\
$\mathbf{1 5 5 8 / 5 9}$ & $370.520,0$ & 114,2 & $0,33(1518 / 19-1558 / 59)$ \\
$\mathbf{1 5 9 2 / 9 3}$ & $324.783,2$ & 100,1 & $-0,39(1558 / 59-1592 / 93)$ \\
$\mathbf{1 6 3 3 / 3 4}$ & $178.597,5$ & 55,0 & $-1,45(1592 / 93-1633 / 34)$ \\
$\mathbf{1 6 6 5 / 6 6}$ & $155.022,3$ & 47,8 & $-0,44(1633 / 34-1665 / 66)$ \\
$\mathbf{1 6 9 8 / 9 9}$ & $192.399,9$ & 59,3 & $0,66(1665 / 66-1698 / 99)$ \\
\hline
\end{tabular}

* El central de cada trienio. Las rentas, por tanto, son promedios trienales.

Fuentes: ACAv, Libros de Cuentas de la Mesa Capitular, 1518-1700.

cabe descartar, al respecto, los efectos depresivos sobre la demanda de labrantíos derivados de la grave crisis demográfica que afectó a la Corona de Castilla en 1506$1508^{37}$. Lo cierto es que, hasta 1529/30, el aumento fue casi imperceptible, operándose a una tasa anual del 0,06 por 100; posteriormente, entre esa fecha y 1558/59, el ritmo promedio de crecimiento se aceleró, alcanzando el 0,43 por 100. Fue en la última fecha citada cuando se registró, en el período estudiado, el volumen máximo de grano ingresado por el cabildo en concepto de renta de las heredades de la muestra.

2) Entre 1558/59 y 1592/93 puede distinguirse la primera subfase de caída de la renta. Con una tasa media de $-0,39$ por 100, se caracterizó por un descenso casi equivalente al crecimiento habido en la primera mitad del siglo, situándose el volumen de grano ingresado en 1592/93 en un nivel muy parecido al de 1518/19. No obstante, esta aparente moderación del movimiento a la baja oculta una fuerte contracción, entre 1558/59 y 1567 / 68 (en nueve años, la renta cayó un 17,4 por 100, lo que supone una tasa media de $-2,10$ por 100), seguida de una ligera recuperación, entre 1567/68 y 1592/93 (un aumento del 6 por 100, a una tasa media del 0,24 por 100).

3) Hacia 1592/93 se inició el segundo subperíodo de descenso de la renta, cuarenta años aciagos que, hasta 1633/34, registraron una fortísima caída, del orden del 45 por 100 , operada a una tasa media anual de $-1,45$ por 100 . En su transcurso, cortos lapsos de auténtico desplome de aquélla (como 1609/10-1612/13 y 1630/31- 
1632/33) se combinaron con fases algo más largas de deterioro menos acentuado (1599/1600-1607/08) o de relativo estancamiento (1612/13-1620/21). Ya desde finales del primer decenio del siglo XVII, el cabildo catedralicio, advirtiendo la magnitud de la contracción, puso en marcha diversas estrategias, entre las que destaca la inclusión en los contratos de arrendamiento de una nueva cláusula, llamada de reconducción, la cual contemplaba que aquéllos se renovasen por la tácita y no se rescindiesen hasta que una de las partes lo solicitara formalmente. En una coyuntura como 1630/31-1632/33, la intensa mengua de la cantidad de grano ingresada (durante dos años aquélla se despeñó a un ritmo promedio de $-9,35$ por 100) se debió, tanto a la caída de la renta extraída de numerosos labrantíos, como a la imposibilidad de hallar, para muchos otros, cultivadores dispuestos a tomarlos a su cargo. De hecho, en el lapso citado, cincuenta fincas de las incluidas en la muestra quedaron $\sin$ renteros $^{38}$.

4) La tercera, y última, subfase de descenso de la renta trascurrió entre 1633/34 y 1665/66. En contraste con la anterior, el ritmo de caída se desaceleró (fue de -0,44 por 100), los episodios de desplome desaparecieron e, incluso, se registró un repunte (en 1643) por vez primera en mucho tiempo. Sin embargo, la dimensión del deterioro del volumen de grano ingresado por el cabildo, tras un siglo de quebrantos, era descomunal. Si resulta llamativo que la cantidad calculada para 1665/66 sólo implique el 42 por 100 del máximo aflujo anual de rentas en grano, correspondiente a 1558/59, aún lo es más que únicamente suponga el 49 por 100 del ingresado en $1518 / 19$.

5) Por último, entre 1665/66 y 1698/99, las rentas en especie percibidas por el cabildo de Ávila tendieron a recuperarse, al compás de una tasa promedio anual del 0,66 por 100 . Pero el vigor de dicha recuperación fue apreciablemente mayor luego de 1680/81 que antes de esta fecha, lapso en el que predominó el estancamiento. De hecho, el ritmo promedio de aumento sólo alcanzó el 0,26 por 100 en 1668/69$1680 / 81$, mientras que entre $1680 / 81$ y 1698/99 fue del 0,99 por 100. En todo caso, conviene destacar que, en los últimos años del siglo XVII, las rentas en grano percibidas por el cabildo abulense sólo suponían el 52 por 100 de las ingresadas en 1558/59, el momento culminante del siglo XVI, y apenas el 59 por 100 de las entrojadas en 1518/19.

En resumen, la trayectoria seguida por la renta de la tierra en el norte de la provincia de Ávila en los siglos XVI y XVII resultó profundamente marcada, más allá del moderado aumento observado en la primera mitad del Quinientos, por el fortísimo descenso que describió, sobre todo, en los dos primeros tercios del Seiscientos.

38 Como, en esas fechas, las 182 heredades de la muestra estaban divididas en 248 predios, ello equivale a la quinta parte de estos últimos (ACAv, Libros de Cuentas de la Mesa Capitular, 1633). 


\section{La renta de la tierra y su evolución en Ávila: una perspectiva com- parada}

La reconstrucción del recorrido descrito por la renta de la tierra en Ávila entre comienzos del siglo XVI y finales del XVII permite completar lo que sabíamos, para ese período, sobre la evolución de la citada variable en la meseta castellana; por ello, resulta obligado referir a dicho espacio el grueso de la comparación. También es aconsejable contrastar, siquiera de modo puntual, ese perfil con el establecido para otras zonas de España, Francia e Italia. En el Cuadro 5 y en el Gráfico 2, junto a la serie de Ávila, se incluyen algunas de las más largas y completas de que se dispone para el territorio histórico de Castilla y León ${ }^{39}$.

Como puede observarse, el movimiento de la renta de la tierra en cuatro zonas de la submeseta norte entre 1517 y 1700, dentro de una tónica de general similitud, presenta diversas particularidades en su cronología y en su intensidad.

Si fijamos la atención, primero, en el siglo XVI, un período dominado, en general, por el crecimiento de la variable que nos ocupa, puede apreciarse que los datos de Ávila vienen a confirmar la existencia de una primera etapa de atonía de la renta de la tierra, la cual abarcaría hasta el decenio de 1530: en Segovia, el estancamiento sería la tendencia dominante entre 1519 y 1527; en Ávila, entre 1517 y $1530^{40}$.

Las evidencias disponibles, reforzadas por el caso abulense, parecen apuntar a que, tras el fuerte aumento de la renta que caracterizó a la segunda parte del siglo $\mathrm{XV}-\mathrm{y}$, en especial, a su último tercio-, dicha tendencia se desaceleró profundamente en tierras castellanas durante los primeros decenios del siglo $\mathrm{XVI}^{41}$. Existen indicios, para otros territorios peninsulares, de comportamientos no muy distintos. En Sevilla, la renta de la tierra cayó un 16 por 100 entre 1525 y 1545; en Cataluña, por su parte, después de crecer en los primeros años del Quinientos, la renta descendió, aproximadamente, entre 1521 y 1530, y su recuperación posterior fue especialmente lenta hasta $1539^{42}$. Fuera de España, el intenso aumento de la renta de la tierra en la

39 En los casos de Ávila, Segovia y Zamora, he traducido las rentas percibidas en fanegas de grano a kilogramos según los coeficientes citados en la nota 31. En el de León, he empleado los facilitados por José Antonio Sebastián, a quien agradezco su gentileza: 42 kilogramos por fanega de trigo, 34,13 por fanega de cebada y 38,83 por fanega de centeno.

40 En el mismo lapso, la renta también tendió a estancarse en diversas áreas de Tierra de Campos; en otras, aunque se aprecian alzas, éstas no tuvieron un carácter sostenido (Yun, 1987, pp. 170-177). En el Oriente leonés, la renta de siete fincas del monasterio de Sandoval sólo creció un 2,7 por 100 entre 1510/13 y 1518/28; la de otras once sufrió un ligero retroceso, del 0,6 por 100, entre 1518-1528 y 1529-1537 (Sebastián, 1990, p. 60).

41 Como han señalado, entre otros, Casado (1979) y (1991), y Sebastián (1990) y (1992).

42 Para Sevilla, González Mariscal (2005). Para Cataluña, Durán (1985). La renta de la tierra en Pals, en el Bajo Ampurdán, descendió más de un 61 por 100 entre 1518 y 1530. 
CUADRO 5

RENTAS EN GRANO REGISTRADAS EN CUATRO ZONAS DE LA SUBMESETA NORTE, 1517-1700 (números índice, base $100=1592 / 93$ )

\begin{tabular}{crccc}
\hline Años $^{*}$ & Ávila & Segovia & Oriente leonés & Zamora \\
\hline $\mathbf{1 5 1 8 / 1 9}$ & 99,9 & 80,5 & - & - \\
$\mathbf{1 5 5 8 / 5 9}$ & 114,1 & $109,0^{\text {** }}$ & - & - \\
$\mathbf{1 5 6 9 / 7 0}$ & 95,2 & 93,5 & 81,9 & - \\
$\mathbf{1 5 9 2 / 9 3}$ & 100,0 & $100,0^{\text {** }}$ & $100,0^{\star \star *}$ & 100,0 \\
$\mathbf{1 6 1 4 / 1 5}$ & 77,0 & 88,1 & 66,6 & 76,5 \\
$\mathbf{1 6 3 3 / 3 4}$ & 55,0 & 79,6 & 62,1 & 65,7 \\
$\mathbf{1 6 6 5 / 6 6}$ & 47,7 & 71,9 & 51,5 & 51,2 \\
$\mathbf{1 6 8 9 / 9 0}$ & 51,7 & 76,0 & 38,5 & 51,6 \\
$\mathbf{1 6 9 8 / 9 9}$ & 59,2 & 79,9 & 50,1 & 59,9 \\
\hline
\end{tabular}

Tasas de crecimiento (\%)

\begin{tabular}{ccccc}
\hline Períodos & Ávila & Segovia & Oriente leonés & Zamora \\
\hline $\mathbf{1 5 1 8} / \mathbf{1 9 - 1 5 5 8 / 5 9}$ & 0,33 & 0,85 & - & - \\
$\mathbf{1 5 5 8 / 5 9 - 1 5 9 2 / 9 3}$ & $-0,39$ & $-0,24$ & - & - \\
$\mathbf{1 5 9 2 / 9 3 - 1 6 3 3 / 3 4}$ & $-1,45$ & $-0,53$ & $-1,10$ & $-1,02$ \\
$\mathbf{1 6 3 3 / 3 4 - 1 6 6 5 / 6 6}$ & $-0,44$ & $-0,31$ & $-0,58$ & $-0,78$ \\
$\mathbf{1 6 6 5 / 6 6 - 1 6 8 9 / 9 0}$ & 0,33 & 0,23 & $-1,21$ & 0,03 \\
$\mathbf{1 6 8 9 / 9 0 - 1 6 9 8 / 9 9}$ & 1,53 & 0,57 & 2,96 & 1,67 \\
\hline
\end{tabular}

* El central de cada trienio. Los índices, por tanto, están calculados sobre promedios trienales.

** $1554 / 55$.

*** $1590 / 91$.

Fuentes: Para Ávila, rentas del cabildo catedralicio, ACAv, Libros de Cuentas de la Mesa Capitular, 1518-1700. Para Segovia, debo los datos de las rentas del cabildo de la catedral a la gentileza de Ángel García Sanz; véase, también, García Sanz (1986), pp. 299-306. Para Zamora, rentas del cabildo catedralicio, Álvarez Vázquez (1987), pp. 355-415. Para el Oriente leonés, rentas percibidas por el monasterio de Sandoval, Sebastián (1992), pp. 1.121 y ss.

segunda mitad del Cuatrocientos está atestiguado en el norte de Francia ${ }^{43}$, si bien, en el centro y en el sur, su evolución se caracterizó por cierta estabilidad, que se mantuvo durante la primera parte del siglo $\mathrm{XVI}^{44}$. En Sicilia, aunque la renta continuó creciendo durante los primeros veinte años del Quinientos, descendió claramente en el curso de los veinte siguientes ${ }^{45}$.

43 Hoffman (2000), p. 90; Jacquart (1974), p. 46; Le Roy Ladurie y Morineau (1977), pp. 521-522. En ocho posesiones del cabildo catedralicio de Nôtre-Dame de París, la renta por unidad de superficie creció un 56 por 100 entre 1475 y 1500 (Desaive, 1972).

44 Constant (1978); Le Roy Ladurie (1966), pp. 1.022-1.023.

45 En Alessandria della Rocca y en Marsala (Sicilia), la renta por unidad de superficie creció un 58 por 100 entre 1501/10 y 1511/20; desde 1511/20 hasta 1531/40, se redujo un 42 por 100 (Cancila, 1978). 


\section{GRÁFICO 2}

RENTAS EN GRANO REGISTRADAS EN CUATRO ZONAS DE LA SUBMESETA NORTE, 1517-1700

(promedios trienales en números índice, base $100=1583-1585$ )

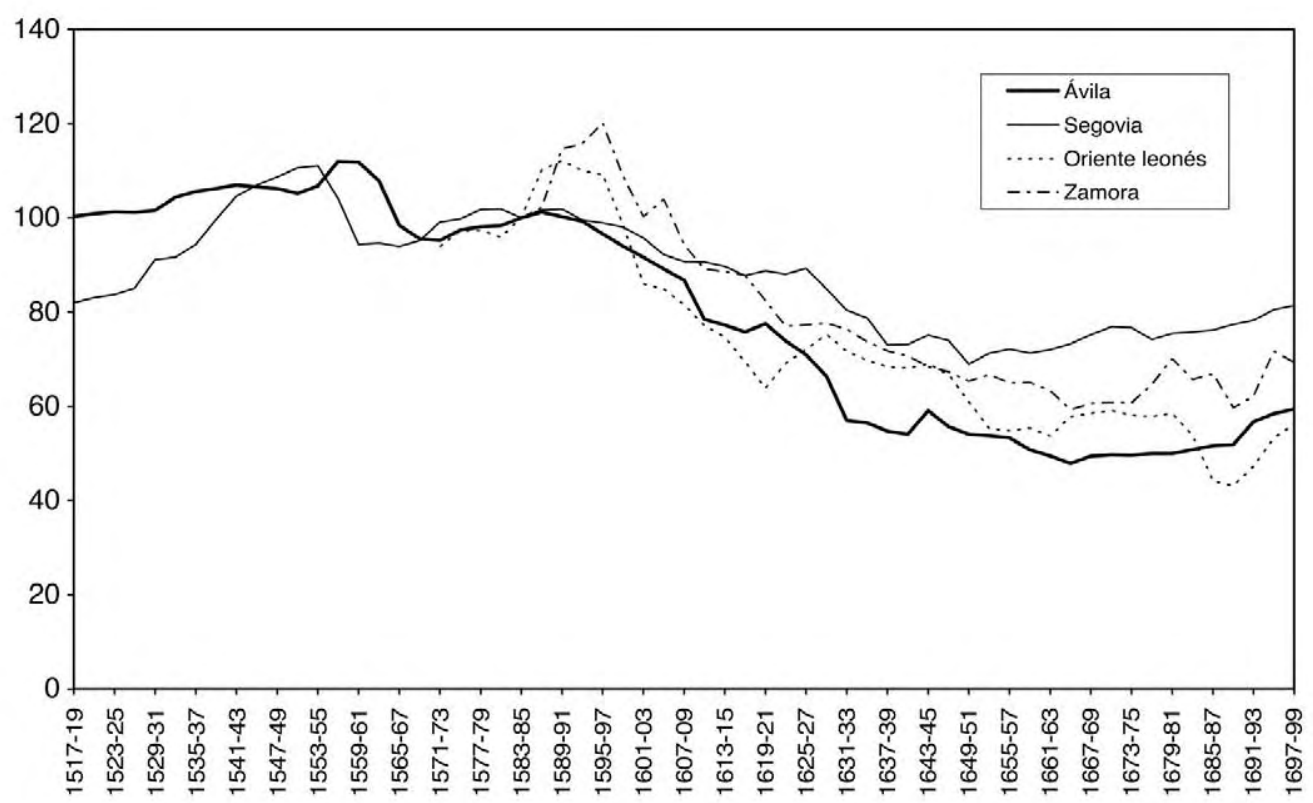

Fuentes: Las mismas del Cuadro 5.

En la submeseta norte, en todo caso, el retorno al alza de la renta de la tierra se generalizó conforme transcurría el decenio de 1530, resultando bastante más intenso en tierras segovianas que en tierras abulenses (véanse el Gráfico 2 y el Cuadro 5). Aunque esa diferencia de ritmo debió de responder a varios factores, uno que resulta indispensable considerar es el de los regímenes de tenencia que los cabildos de Segovia y de Ávila empleaban a la hora de afrontar la explotación indirecta de sus heredades. El giro dado al respecto por los capitulares segovianos, a favor del arrendamiento renovable por plazos cortos, en la segunda mitad del siglo XV, se profundizó durante la primera del $\mathrm{XVI}^{46}$. Por su parte, los canónigos abulenses, aunque también venían mostrando su predilección, como otros grandes terratenientes castellanos, por los arrendamientos cortos frente a los censos enfitéuticos, no introdujeron 
cambios, durante la primera mitad del Quinientos, en los modos de cesión de las haciendas que componen la muestra aquí utilizada ${ }^{47}$.

Como puede apreciarse, la citada trayectoria alcista culminó en Ávila, como en Segovia, a mediados o finales del decenio de $1550^{48}$. Desde entonces, se produjo una notable caída, que en Segovia tocó fondo en 1566/67 y en Ávila en 1572/73; posteriormente, las rentas tornaron a crecer en ambos casos, si bien los nuevos máximos alcanzados en los años de paso del decenio de 1580 al de 1590 quedaron bastante por debajo de los registrados en el decenio central del siglo. Ello contrasta (véase el Gráfico 2) con las trayectorias seguidas por las rentas leonesas y zamoranas, cuya escalada durante la segunda mitad del siglo XVI continuó hasta comienzos o mediados del decenio de 1590. Con las salvedades de rigor, pues las dos últimas series citadas comienzan después de $1560^{49}$, parecen distinguirse dos modelos en el crecimiento registrado por la renta de la tierra, en la meseta castellana, durante el siglo XVI: uno, donde el alza culminaría, aproximadamente, a mediados de la centuria, y otro, donde aquélla se prolongaría hasta finales de la misma ${ }^{50}$. Quizá entre ambos extremos se situase el cénit de un incremento de la renta de la tierra cuyas raíces se hundían en el siglo XV en la mayor parte de los territorios peninsulares; así, en Sevilla, el citado aumento se prolongó hasta 1564; en Cataluña y en el País Valenciano, las rentas crecieron considerablemente, al parecer, hasta $1570^{51}$. En este caso, además, las cosas no serían muy distintas en tierras francesas y sicilianas. En el norte y el centro de Francia, la renta remontó de forma generalizada hasta el decenio de 1580, para descender a continuación, cerrándose la centuria con caídas de consideración ${ }^{52}$. En Sicilia, en cambio, se crecimiento se alargó hasta el decenio de $1620^{53}$.

47 En la submeseta norte, muchos grandes propietarios escogieron el arrendamiento temporal como forma predilecta de ceder el usufructo de sus labrantíos en el último tercio del siglo XV y los primeros decenios del XVI. Pueden mencionarse, junto a los cabildos catedralicios citados, los de Zamora y Burgos, el monasterio leonés de Sandoval y el Hospital de San Antolín de Palencia. Véanse, respectivamente: Álvarez Vázquez (1987), pp. 32-43, Casado (1987), pp. 341-369, y (1991), p. 81; Sebastián (1999), p. 334, y Marcos Martín (1985), pp. 203-222. En general, Marcos Martín (2000), p. 216 y ss.

Algo similar parece ocurrir en el caso de las rentas percibidas por el monasterio de Rioseco, en el noroeste de Burgos, que alcanzaron su máximo en 1556/57, las cuales también he reconstruido (AHN, Clero, libros 1.192, 1.409-1.413, y 1.416-1.419). No obstante, la serie resultante es corta y contiene demasiadas lagunas como para compararse con las que figuran en el Gráfico 2, por lo que he optado por no emplearla en este trabajo. Sus autores, no obstante, cuentan con suficientes indicios como para sostener que, efectivamente, el alza de la renta registró sus máximos, durante el Quinientos, en el Oriente leonés y en Zamora, en el último decenio del siglo (Álvarez Vázquez, 1987, pp. 355 y ss., y Sebastián, 1992, pp. 780 y ss.). O, incluso, algo más allá, como en Palencia, donde la renta continuó aumentando hasta entrado el decenio de 1610 (Marcos Martín, 1985, pp. 211-214).

51 Véanse, respectivamente, González Mariscal (2005), Durán (1985), y Ardit (1993).

52 Veyrassat-Herren y Le Roy Ladurie (1968); Desaive (1972); Jacquart (1974) y (1975); Le Roy Ladurie y Morineau (1977); Pavard (1978), y Hoffman (2000).

53 Cancila (1978). 
Sea como fuere, en la submeseta norte la unanimidad se restableció durante los dos primeros tercios del siglo XVII: en las cuatro zonas consideradas, la renta de la tierra se vino abajo, situándose al final de dicho lapso, salvo en Segovia, en niveles próximos a la mitad de los alcanzados en el último decenio del siglo XVI. Y en las cuatro, el descenso fue mucho más pronunciado en el primer tercio del Seiscientos que en el segundo, bordeando el desplome (véase el Cuadro 5) en Ávila, el Oriente leonés y Zamora. En Segovia, las rentas descendieron menos y a un ritmo promedio menos intenso durante todo el período, lo que, a la altura de $1665 / 66$, contrasta especialmente con el hundimiento de las rentas abulenses. Aunque no cabe ensayar aquí una explicación más detallada de esa diferencia, uno de los factores que hubo de contribuir a la misma debió de ser el que, en Ávila, los cultivadores directos dependiesen del usufructo de predios ajenos en mayor medida que los segovia$\operatorname{nos}^{54}$. Desde que la coyuntura económica comenzó a deteriorarse, en el último tramo del Quinientos, es probable que el porcentaje de explotaciones agrarias inviables se incrementase a un ritmo algo mayor en el área abulense que en la segoviana. Quizá algo semejante cabría apuntar para el Oriente leonés. Por otra parte, resulta tentador vincular la trayectoria seguida por la renta de la tierra con la descrita por los efectivos demográficos, aunque esta última constituya sólo uno de los factores a considerar para explicar aquélla y la citada relación no tenga un carácter directo ni instantáneo (véase el Gráfico 3). Es probable que en Ávila, como en Segovia y en el Oriente leonés, la renta de la tierra no mostrase claros signos de recuperación, en el transcurso del siglo XVII, mientras no ocurriese otro tanto con las cifras demográficas ${ }^{55}$.

Durante el último tercio del siglo XVII, la tendencia descrita por la renta de la tierra en la submeseta norte comenzó a cambiar; al respecto, sin embargo, los casos de Ávila y Segovia vuelven diferir de los concernientes al Oriente leonés y Zamora. En tierras segovianas, consecuentemente con un hundimiento menos aparatoso, el cambio se adelantó; de hecho, la renta tocó fondo a comienzos del decenio de 1650 si bien, hasta mediado el siguiente, se mantuvo prácticamente estancada; en Ávila, el mínimo, a mediados del decenio de 1660, coincidió con el punto de inflexión. En ambos territorios, de todos modos, la tendencia a la recuperación se manifestó claramente desde 1665/66 (véase el Cuadro 5), con una precocidad relativa que recuerda lo

54 Tanto las cifras de población activa agraria del Censo de Godoy de 1797, como las Respuestas Particulares del Catastro de Ensenada, apuntan a que la propiedad de la tierra estaba más concentrada en Ávila que en Segovia (véanse, respectivamente, Gil, 1981, y García Sanz, 1986). Este último autor señala que, en la provincia de Segovia, a mediados del siglo XVIII, "las dos terceras partes de la superficie eran propiedad de los campesinos cultivadores directos", si bien sólo generaban "poco más de la mitad del valor del producto bruto anualmente conseguido" (García Sanz, 1986, p. 264). 


\section{GRÁFICO 3}

RENTA Y NÚMEROS DE BAUTIZADOS EN LA MITAD NORTE DE ÁVILA, 1517-170056

(números índice, base $100=1580-1589$ )

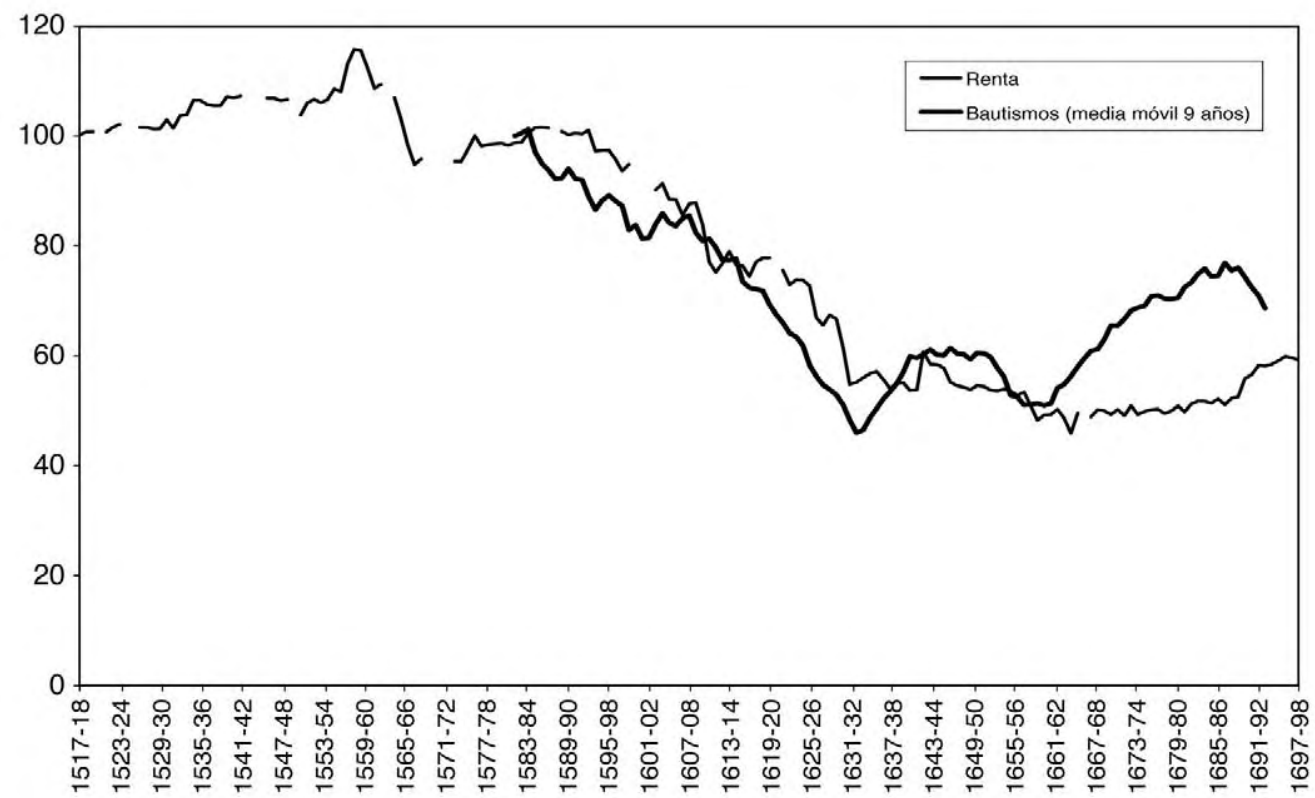

Fuentes: ACAv, Libros de Cuentas de la Mesa Capitular, 1518-1700; ADAv, Libros de bautismos de las parroquias de Fontiveros, Riocabado, Adanero, Flores de Ávila, Madrigal, Palacios de Goda, Muñosancho y Villamayor, Viñegra de Moraña, Riofrío y Cabañas y Gemuño.

sucedido en Cataluña ${ }^{57}$. Pero no ocurrió lo mismo en otros espacios de la meseta castellana. En Zamora, los mínimos de mediados de los años sesenta, tras una aparente recuperación (véase el Gráfico 2), volvieron a registrarse a finales de los ochenta, arrojando la evolución de la renta un balance decepcionante entre 1665/66 y 1689/90. En el Oriente leonés, la renta, tras permanecer estancada en el decenio de 1670, conoció un último hundimiento en la de $1680^{58}$.

En suma, a la vista del Cuadro 5, puede afirmarse que, en la submeseta norte, la renta de la tierra sólo recuperó la senda del crecimiento, de manera clara, en el últi-

\footnotetext{
56 Sin incluir la ciudad de Ávila.

57 En el Principado, la renta comenzó a recuperarse en 1662 (Durán, 1985).

58 En Palencia acaeció algo similar: el descenso de la renta sólo tocó fondo en los años ochenta (Marcos Martín, 1985, pp. 211- 214).
} 
mo decenio del siglo XVII. De modo semejante, en la zona central de Francia, la renta no volvió a crecer hasta $1690^{59}$; en Sicilia, por su parte, tras descender desde 1620, no inició su recuperación hasta del decenio de $1680^{60}$.

Importa subrayar, en todo caso, los bajos niveles en que se situaba la renta de la tierra en el ámbito de Castilla y León, en relación a finales del Quinientos, todavía a comienzos del siglo XVIII: en 1698/99 era inferior, respecto de 1592/93, en un 20 por 100 en Segovia, en un 40 por 100 en Ávila y Zamora, y en un 50 por 100 en el Oriente leonés. Y es que, debe insistirse, lo que imprime carácter a la trayectoria seguida por la citada variable en la submeseta norte, en los dos siglos estudiados, es su descomunal contracción entre mediados o finales del siglo XVI y algún momento, generalmente muy avanzado, del XVII; y esto es, precisamente, lo que las rentas ingresadas por el cabildo de Ávila vienen a confirmar sin sombra de duda. Si se comparan los máximos y los mínimos registrados en cada una de las cuatro zonas aludidas en esos doscientos años, se observa, de otro modo, la gran magnitud del citado descenso, el cual enseñoreó, en promedio, un siglo. En Segovia, entre 1554/55 y 1650/51, la renta cayó un 38 por 100; en Zamora (1596/97$1665 / 66)$ un 51 por 100; en Ávila (1558/59-1665/66) un 58 por 100; y en el Oriente leonés (1590/91-1689/90) un 62 por 100.

\section{El tamaño de los predios y la renta de la tierra}

En el norte de Ávila, al igual que en otras zonas de Castilla, de España y de Europa, la cuantía de la renta por unidad de superficie decrecía a medida que aumentaba el tamaño de las fincas arrendadas o cedidas a censo ${ }^{61}$. En tierras abulenses, a mediados del siglo XVI, la renta por unidad de superficie en las fincas de más de 50 hectáreas era un 19, un 14 y un 12 por 100 inferior a la de los predios cuya extensión se situaba en los intervalos 1,5-9,9 hectáreas, 10-24,9 hectáreas y 25-49,9 hectáreas, respectivamente (véase el Cuadro 6) ${ }^{62}$. De modo que, hacia 1550, todavía en la fase expansiva de la economía castellana, tales diferenciales eran significativos, pero no abismales.

59 Jacquart (1975). La trayectoria fue distinta en el norte y en el sur del territorio francés, donde la renta de la tierra tornó a elevarse ya en el decenio de 1630, iniciando posteriormente, en el de 1670, una nueva etapa recesiva, la cual desembocó en un descenso generalizado hasta entrado el siglo XVIII. Véanse Le Roy Ladurie (1966); Veyrassat-Herren y Le Roy Ladurie (1968); Jacquart (1975); Pavard (1978), y Hoffman (2000).

Cancila (1978).

61 Hoffman (2000), pp. 54-60, ha estimado que en algunas propiedades de Nôtre-Dame de París, la renta por hectárea disminuía un 8,5 por 100 cuando el tamaño de los predios se doblaba.

62 Las tasas de la renta se han calculado como se indica en la nota 26. 
CUADRO 6

TASAS DE LA RENTA DEL CABILDO DE ÁVILA SEGÚN EL TAMAÑO DE LAS FINCAS, 1549

Dimensión en hectáreas

\begin{tabular}{lrl}
\hline $\mathbf{1 , 5}$ a 9,9 & 27 & 0,833 \\
$\mathbf{1 0}$ a 24,9 & 9 & 0,784 \\
$\mathbf{2 5}$ a 49,9 & 7 & 0,766 \\
$\mathbf{5 0}$ y más & 13 & 0,675 \\
\hline & 56 & 0,729 \\
\hline
\end{tabular}

Fuentes: ACAv, Libros de Cuentas, 1518-1700; AHPAv, Respuestas Particulares del Catastro de Ensenada de los lugares señalados en la nota 26 .

Interesa conocer los contrastes de las rentas por unidad de superficie según el tamaño de las fincas en un determinado momento, pero también la evolución temporal de aquéllos. Se desconoce la superficie de algunas de las propiedades del cabildo catedralicio que forman parte de la muestra empleada en esta investigación; de ahí que haya tenido que emplear un procedimiento no óptimo de aproximación a la trayectoria de los diferenciales de renta por unidad de superficie de acuerdo a la dimensión de los predios. Para alcanzar ese objetivo, he recurrido a un procedimiento sencillo: comparar las trayectorias de los ingresos obtenidos por el cabildo abulense en las cinco heredades que le proporcionaban las mayores rentas territoriales (éstas se hallaban, casi con toda seguridad, entre los predios de mayor dimensión) y en las quince fincas que le reportaban las menores (éstas formaban parte, sin duda, de los predios de tamaño más reducido). Para que tal comparación, que se recoge en el Gráfico 4, cobre sentido, resulta necesario suponer que las dimensiones de dichas fincas no cambiaron, o sólo registraron modificaciones insignificantes, en todo el período objeto de análisis (1517/1518-1699/1700), y que las calidades de sus suelos no diferían en exceso, supuestos que considero pueden mantenerse.

El Gráfico 4 revela que las quince rentas más pequeñas fueron las que menos crecieron durante los seis primeros decenios del Quinientos y que las cinco mayores fueron las que más cayeron en el Seiscientos ${ }^{63}$. Ello apunta a que fueron los grandes arrendatarios los más castigados por la crisis de finales del siglo XVI y de 


\section{GRÁFICO 4}

EVOLUCIÓN DE LAS CINCO MAYORES Y DE LAS QUINCE MENORES RENTAS EN GRANO PERCIBIDAS POR EL CABILDO DE ÁVILA, 1517-1700

(números índice, base 100 = 1518-1528)

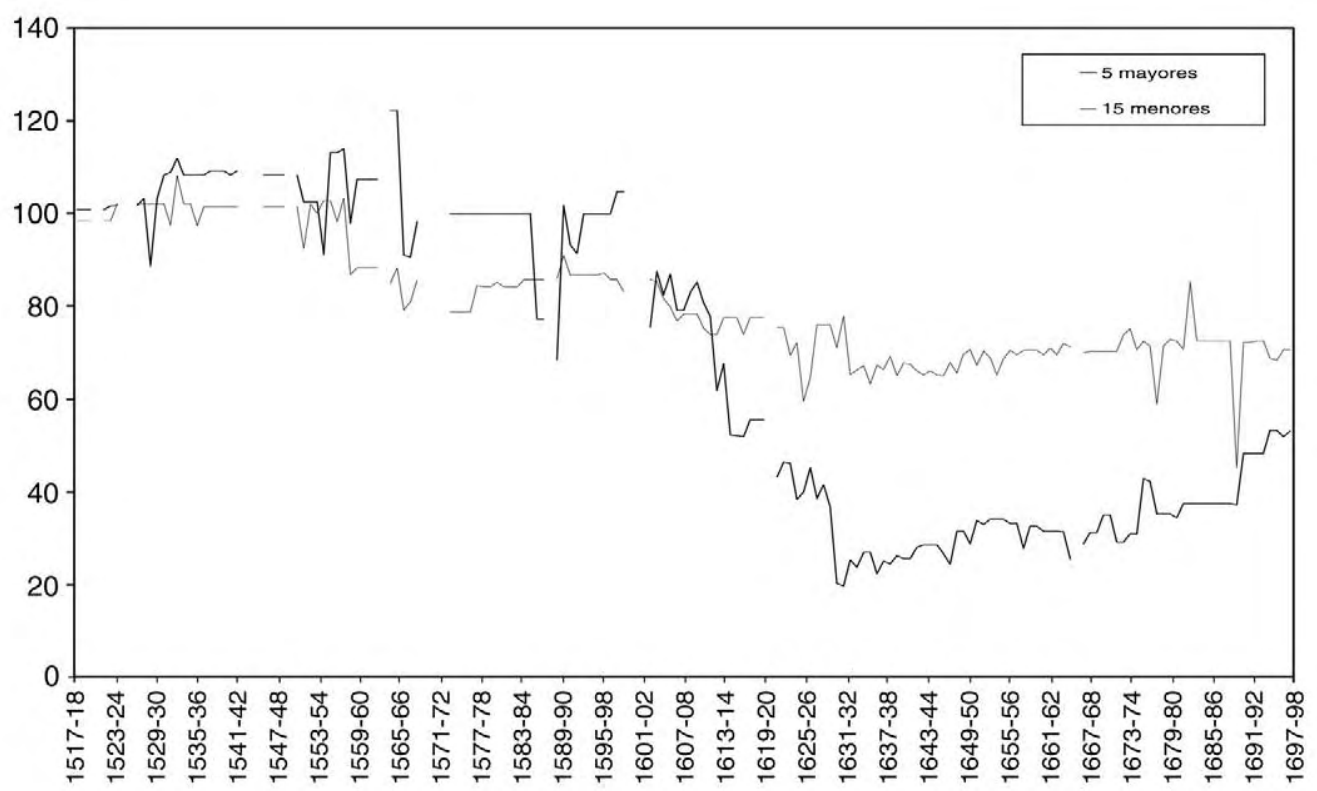

Fuente: ACAv, Libros de Cuentas de la Mesa Capitular, 1518-1700.

la primera mitad del siglo $\mathrm{XVII}^{64}$. El descenso de la renta en las grandes fincas comenzó a cobrar auténtica intensidad en 1599/1600 (algo más tarde que en el conjunto de la muestra); entre esa fecha y 1632/33, momento en el cual alcanzó el mínimo del período, aquélla cayó a una tasa media anual del 4,79 por 100 . Por su parte, el descenso fuerte en las 15 rentas menores no comenzó hasta 1603/04; entre este año y 1666/67, la caída se operó a una tasa media anual de 1,51 por 100 . Desde 1634 , ambas tendieron a recuperarse, pero fueron las cinco rentas mayores las que lo hicieron a mayor velocidad. De 1633/34 a 1697/98, éstas retomaron la senda ascendente a un ritmo promedio anual del 1,51 por 100 , mientras que las 15 menores lo

64 Las cinco mayores se percibían en Albornos, Cantiveros, Cardillejos, Montalvo de Moraña y Muñogrande; las 15 menores en Aldealamula, Blascosancho, Bodón, Castilblanco, Helechosa, Monsalupe, Morañuela, Muñochás del Valleamblés, El Orrio, Parral, Saornil de Voltoya, Tornadizos de Arévalo, Velayos, Villacomer y Zarzalejo. Se trata de arrendamientos en todos los casos. 
hicieron a un 0,18 por 100. En cualquier caso, hacia 1700, las rentas de las fincas de mayor tamaño estaban bastante más lejos de recuperar los valores promedios del decenio 1518-1528 que las de los predios de menor dimensión.

En suma, el Gráfico 4 pone de manifiesto que los diferenciales de renta por unidad de superficie entre las fincas de menor y de mayor tamaño se ampliaron notablemente durante la primera mitad del siglo XVII. Ello hubo de incentivar a los grandes propietarios a subdividir sus fincas y a cederlas a pequeños colonos.

El deseo de minimizar riesgos y costes de transacción constituía uno de los objetivos básicos de los grandes rentistas. Tal prioridad debía de estar muy presente cuando tenían que elegir entre ceder el usufructo de sus heredades en parcelas de extensa superficie a grandes arrendatarios o a mancomunidades de cultivadores, $\mathrm{o}$ en parcelas de reducido tamaño a pequeños locatarios. Las tres opciones tenían ventajas e inconvenientes. La primera suponía operar con costes de transacción relativamente reducidos, proporcionando las cesiones a campesinos acomodados cierta seguridad en el cobro de la renta, excepto si la coyuntura se tornaba muy desfavorable para los grandes arrendatarios; ahora bien, si la renta no se percibía, independientemente del motivo, la disminución de los ingresos era mucho mayor que si no se recaudaba la renta exigida por un pequeño predio. La opción de ceder las heredades en grandes parcelas a campesinos mancomunados tenía, al igual que la anterior, la ventaja de reducir costes de transacción, a la vez que proporcionaba una seguridad mayor de percibir la renta, al responder solidariamente todos los renteros de su pago; pero tenía el mismo inconveniente de la opción anterior; además, si surgían problemas, éstos no se dirimían con uno o dos arrendatarios, sino con un colectivo que, en ocasiones, podía abarcar a todo un concejo. Ceder el usufructo en pequeños lotes implicaba asumir costes de transacción mayores que en los casos anteriores, así como, quizá, una mayor inseguridad en el cobro de las rentas y una mayor dificultad para ejercer un estrecho control sobre las fincas; no obstante, en caso de no cobrarlas, la reducción de los ingresos era menor que cuando no se percibía una gran renta; además, la competencia entre potenciales usufructuarios individuales, salvo en períodos de gran prosperidad para los campesinos acomodados, solía ser bastante mayor.

El cabildo catedralicio de Ávila, como gran propietario, seguramente trató de elegir en cada momento las fórmulas de cesión de sus heredades que le ofrecieran mayores ventajas netas. No obstante, su margen de maniobra tuvo que verse notablemente limitado por la capacidad de presión y negociación de los concejos y de los usufructuarios de sus predios. En general, las grandes instituciones eclesiásticas eran proclives a renunciar a maximizar completamente sus rentas en aras de preservar su imagen y de evitar conflictos sociales. Sin embargo, durante la primera mitad del siglo XVI, caracterizada por el incremento de la población y de las rentas y por una coyuntura económica relativamente favorable a los grandes locatarios, el cabildo 
abulense desarrolló una política de cesiones de lotes de tierra de dimensiones notables, tanto a arrendatarios individuales como a mancomunidades de labradores. Desde finales del segundo tercio del Quinientos, cuando se inició un período caracterizado por un paulatino deterioro de las economías campesinas, los capitulares no tuvieron más remedio que rebajar el canon cobrado a sus arrendatarios. Además, como los diferenciales de renta por unidad de superficie de acuerdo al tamaño de los predios aumentaron sensiblemente en la primera mitad del siglo XVII, los capitulares abulenses acabaron fragmentando sus fincas ${ }^{65}$; es probable que algunas de estas parcelaciones fuesen voluntarias (a fin de evitar una caída aún mayor de la renta de la tierra), pero la mayoría debió de resultar forzada por la aguda escasez de campesinos prósperos, dispuestos a arrendar predios de gran dimensión, en un contexto de creciente presión fiscal y de fuerte descenso de la demanda de cereales como consecuencia de la decadencia urbana. Por otro lado, las situaciones de abandono de tierras fueron aprovechadas por el cabildo catedralicio para transformar censos enfitéuticos en contratos de arrendamiento, pero incluyendo en éstos la cláusula de reconducción. Desde 1680, en una nueva etapa de crecimiento de la renta, los capitulares abulenses, lentamente, volvieron a unir parcelas para constituir unidades de explotación de mayor tamaño.

En definitiva, la profunda crisis de finales del siglo XVI y de la primera mitad del siglo XVII indujo una mayor parcelación de las fincas rústicas del cabildo catedralicio de Ávila y un cambio apreciable en la estructura del campesinado. El debilitamiento de los medianos y grandes arrendatarios contribuyó a polarizar aún más la estructura social y a introducir al desarrollo agrario castellano por una senda poco favorable para la recuperación, primero, y la expansión, después, del mundo urbano de la región.

\section{Conclusiones}

Hacia 1530, la renta de la tierra suponía en torno al 24,5 por 100 del producto bruto en la parte septentrional de la provincia de Ávila. Ese porcentaje aún aumentaría algo más de un 10 por 100 entre 1530 y finales del decenio de 1560 . Aunque en otros territorios españoles se han estimado, para ese mismo período, tasas aún más elevadas, no cabe la menor duda de que el pago de la renta suponía para los arrendatarios abulenses una carga muy pesada.

65 En 1519, el patrimonio capitular que compone la muestra analizada estaba formado por 94 predios, en 1633 por 248, y en 1670 por 258. ACAv, Libros de Cuentas de la Mesa Capitular, 1518-1700. 
En el norte de Ávila, la renta de los labrantíos creció modestamente en los seis primeros decenios del siglo XVI (un 14 por 100 de 1518/19 a 1558/59), descendió de un modo abrupto en los cuatro últimos del Quinientos y en los dos primeros tercios del Seiscientos (un 58 por 100 de 1558/59 a 1665/66) y se recuperó parcialmente en el último tercio del siglo XVII (creció un 24 por 100 de 1665/66 a 1698/99). De modo que el panorama de esas dos centurias está marcado, ante todo, por la larga duración y la intensidad del movimiento depresivo. Además de ser poco enérgica, la tendencia alcista de la renta de la tierra en el siglo XVI se concentró casi exclusivamente entre 1530 y 1558 . El caso abulense confirma, por tanto, la desaceleración del crecimiento de la renta de la tierra en Castilla y León en los primeros decenios del siglo XVI, tras el fuerte ascenso que había registrado en la segunda mitad del XV.

En términos relativos, la caída de la renta de los labrantíos fue bastante intensa en el norte de Ávila, pero aún lo fue un poco más en el Oriente leonés (un 58 frente a un 61,5 por 100). Si nos fijamos en la duración del movimiento depresivo de esa variable, el norte de Ávila se sitúa en vanguardia entre los casos conocidos: en ninguna otra zona aquél superó el centenar de años. Sin duda, el territorio estudiado constituyó una de las áreas españolas en las que la magnitud de la caída de la renta de la tierra de los predios de "pan llevar" fue mayor. En cualquier caso, este trabajo también constituye una evidencia más en favor de la tesis de la severidad de la contracción económica en la Castilla de los decenios finales del XVI y de la primera mitad del XVII.

Lo mismo que otras áreas peninsulares y europeas, la renta por unidad de superficie era, en el norte de Ávila, mayor en las parcelas más pequeñas que en las que tenían una extensión significativamente superior. Además, esa diferencia se amplió notablemente en los años finales del siglo XVI y en la primera mitad del XVII, lo que sugiere que fueron los grandes arrendatarios el grupo rural más castigado por la profunda contracción económica de dicho período. El descenso especialmente acusado de la renta de los mayores predios y, sobre todo, la aguda escasez de campesinos capaces de movilizar cantidades relativamente importantes de fuerza de tracción animal y de mano de obra, indujeron al cabildo catedralicio abulense a parcelar no pocas de sus heredades y a sustituir unos pocos arrendatarios acomodados por un número netamente superior de pequeños. Y ello, que fue un fenómeno no exclusivamente abulense, condicionó el crecimiento agrario posterior y dificultó la recuperación urbana en Castilla. 


\section{Bibliografía}

ÁLVAREZ VÁZQUEZ, José Antonio (1987): Rentas, precios y crédito en Zamora en el Antiguo Régimen, Zamora, Colegio Universitario de Zamora.

AMALRIC, Jean-Pierre (2003): “La propriété de la terre dans l’Europe du sud (Italie, Midi de la France, Espagne): typologie, utilisation, marché", en Il mercato della terra secc. XIII-XVIII, Prato, Istituto Italiano di Storia Economica “F. Datini” y Le Monnier, pp. 97-117.

ARDIT, Manuel (1993): Els homes i la terra al País Valencià (segles XVI-XVIII), 2 vols., Barcelona, Curial.

ARTOLA, Miguel (1977): “Propiedad, asignación de recursos y distribución de rentas en la agricultura del Antiguo Régimen", Estudios de Historia Social, 1, pp. 11-53

BARRIOS GARCÍA, Ángel (1983-1984): Estructuras agrarias y de poder en Castilla. El ejemplo de Ávila (1085-1320), 2 vols., Salamanca, Ediciones Universidad de Salamanca e Institución "Gran Duque de Alba".

BRUMONT, Francis (1984): Campo y campesinos de Castilla la Vieja en tiempos de Felipe II, Madrid, Siglo XXI.

CABEZA RODRÍGUEZ, Antonio (1997): La vida en una catedral del Antiguo Régimen, Valladolid, Consejería de Educación y Cultura.

CANCILA, Orazio (1978): "Sulla rendita fondiaria in Sicilia dalla fine del Quattocento all'Unità d'Italia", en GOY, Joseph y LE ROY LADURIE, Emmanuel (coords.), Prestations paysannes, dîmes, rente foncière et mouvement de la production agricole à l'époque préindustrielle, París, Éditions de l'École des Hautes Études en Sciences Sociales, pp. 174-195.

CARASA SOTO, Pedro (1993): Censo de Ensenada, 1756, Madrid, Centro de Gestión Catastral y Cooperación Tributaria y Tabapress.

CASADO ALONSO, Hilario (1979): La propiedad eclesiástica en la ciudad de Burgos en el siglo XV: el Cabildo Catedralicio, Valladolid, Universidad de Valladolid.

-(1987): Señores, mercaderes y campesinos. La comarca de Burgos a fines de la Edad Media, León, Junta de Castilla y León.

-(1991): "Producción agraria, precios y coyuntura económica en las diócesis de Burgos y Palencia a fines de la Edad Media", Studia Historica. Historia medieval, IX, pp. 67-107.

CATALÁN MARTÍNEZ, Elena (2000): El precio del purgatorio. Los ingresos del clero vasco en la Edad Moderna, Bilbao, Universidad del País Vasco.

CONSTANT, J. M. (1978): “L'évolution de la rente foncière et de la rentabilité de la terre en Beauce aux XVI e et XVII ${ }^{\mathrm{e}}$ siècles", en GOY, Joseph, y LE ROY LADURIE, Emmanuel (coords.), Prestations paysannes, dîmes, rente foncière et mouvement de la production agricole à l'époque préindustrielle, París, Éditions de l'École des Hautes Études en Sciences Sociales, pp. 529-535. 
DESAIVE, Jean-Paul (1972): “A la recherche d'un indicateur de la conjoncture. Baux de Notre-Dame de Paris et de l'abbaye de Montmartre", en GOY, Joseph, y LE ROY LADURIE, Emmanuel (coords.), Les fluctuations du produit de la dîme, conjoncture décimale et domaniale de la fin du Moyen Age au XVIIIe siècle, París, Mouton, pp. 44-57.

DOMÍNGUEZ ORTIZ, Antonio; CAMARERO, Concepción, y CAMPOS, Javier (dirs.) (1991): Vecindario de Ensenada 1759: Ávila, Burgos, Córdoba, Cuenca, Extremadura, Vol. B1, Madrid, Centro de Gestión Catastral y Cooperación Tributaria y Tabapress.

DURÁN I PUJOL, Montserrat (1985): “L'evolució de l'ingrés senyorial a Catalunya (1500-1799)", Recerques, 17, pp. 7-42.

GARCÍA SANZ, Ángel (1981): “Cambio económico y formas de administración de la propiedad rústica del Cabildo de fines del siglo XIII a principios del siglo XIX: una primera aproximación", en VV. AA., Propiedades del Cabildo segoviano, sistemas de cultivo y modos de explotación de la tierra a fines del siglo XIII, Salamanca, pp. 96-107.

-(1985): “La Grange de Nieva, du Monastère du Parral (Ségovie) entre 1739 et 1808", en AMALRIC, Jean-Pierre, y PONSOT, Pierre (dirs.), L'exploitation des grands domaines dans l'Espagne d'Ancien Régime, París, CNRS, pp. 193-221.

-(1986): Desarrollo y crisis del Antiguo Régimen en Castilla la Vieja. Economía y sociedad en tierras de Segovia de 1500 a 1814, 2a ed., Madrid, Akal.

GARCÍA Y GARCÍA, Antonio (dir.) (1993): Synodicon Hispanum. 6. Ávila y Segovia, vol. 6, Madrid, Editorial Católica.

GARRABOU, Ramón, PLANAS, Jordi, y SAGUER, Enric (2001): “Administradores, procuradores y apoderados: una aproximación a las formas de gestión de la gran propiedad agraria en la Cataluña contemporánea", comunicación presentada al VII Congreso de la Asociación Española de Historia Económica, Zaragoza.

GIL CRESPO, Adela (1981): “Estructura agraria en la actual provincia de Ávila a mediados del siglo XVIII", en VV. AA., Homenaje a Antonio Dominguez Ortiz, Madrid, Ministerio de Educación y Ciencia.

GONZÁLEZ MARISCAL, Manuel (2005): "Propiedades y rentas territoriales del cabildo de la Catedral de Sevilla, 1524-1606. Primeros resultados y reflexiones", comunicación presentada al VIII Congreso de la Asociación Española de Historia Económica, Santiago de Compostela.

HOFFMAN, Philip T. (2000): Growth in a Traditional Society. The French Countryside 1450-1815, New Jersey, Princeton University Press.

INE (1984): Censo de Castilla de 1591. Vecindarios, Madrid, Instituto Nacional de Estadística.

JACQUART, Jean (1974): La crise rurale en Ile-de-France (1550-1670), París.

—(1975): “La rente foncière, indice conjoncturel?", Revue Historique, 514, pp. 355-376. 
LE ROY LADURIE, Emmanuel (1966): Les paysans de Languedoc, París, Flammarion.

LE ROY LADURIE, Emmanuel, y MORINEAU, Michel (1977): "Paysannerie et croissance", en BRAUDEL, Fernand, y LABROUSSE, Ernest (dirs.), Histoire Économique et Sociale de la France, París, Presses Universitaires de France, Tomo I, vol. 2, pp. 479-758.

LLOPIS AGELÁN, Enrique, y CUERVO FUENTE, Noemí (2003): “El movimiento de la población en el Sur de Ávila, 1580-1860", en VV. AA., Estudios de Historia y de Pensamiento Económico. Homenaje al profesor Francisco Bustelo García del Real, Madrid, Universidad Complutense, pp. 147-165.

—(2004): “El movimiento de la población en la provincia de Ávila, 1580-1864”, Áreas, 24, pp. 39-65.

LÓPEZ ARÉVALO, Juan Ramón (1966): Un Cabildo Catedral de la Vieja Castilla. Ávila: su estructura jurídica. Siglos XII-XX, Madrid, Consejo Superior de Investigaciones Científicas.

MARCOS MARTÍN, Alberto (1985): Economía, sociedad, pobreza en Castilla: Palencia, 1500-1814, 2 vols., Palencia, Diputación Provincial de Palencia.

-(2000): España en los siglos XVI, XVII y XVIII. Economía y sociedad, Barcelona, Crítica. PAVARD, J.-M (1978): “Le mouvement de la rente foncière dans la plaine de Caen d'après trois échantillons de la fin du XVIe siècle à la Révolution. Bilan provisoire", en GOY, Joseph, y LE ROY LADURIE, Emmanuel (coords.), Prestations paysannes, dîmes, rente foncière et mouvement de la production agricole à l'époque préindustrielle, París, Éditions de l'École des Hautes Études en Sciences Sociales, pp. 693-705.

PÉREZ MOREDA, Vicente (2002): “La población española en tiempos de Isabel I de Castilla", en VALDEÓN, Julio (ed.), Sociedad y economía en tiempos de Isabel la Católica, Valladolid, Ámbito, pp. 13-38.

ROBLEDO HERNÁNDEZ, Ricardo (1984): La renta de la tierra en Castilla la Vieja y León (1836-1913), Madrid, Banco de España.

SEBASTIÁN AMARILLA, José Antonio (1990): “La renta de la tierra en León durante la Edad Moderna. Primeros resultados y algunas reflexiones a partir de fuentes monásticas", Revista de Historia Económica, VIII, 1, pp. 53-80.

-(1992): Agricultura y rentas monásticas en tierras de León. Santa María de Sandoval (1167-1835), 2 vols., Madrid, Universidad Complutense de Madrid.

—(1999): "Del "fuero" al arrendamiento. Tenencia y explotación de la tierra en León entre la Edad Media y la Edad Moderna", Revista de Historia Económica, XVII, 2, pp. 305-341.

VEYRASSAT-HERREN, Béatrice, y LE ROY LADURIE, Emmanuel (1968): “La rente foncière autour de Paris au XVII siècle", Annales. Économies, Sociétés, Civilisations, $23^{\circ}$ Année, 3, pp. 541-555.

YUN CASALILLA, Bartolomé (1987): Sobre la transición al capitalismo en Castilla: economía y sociedad en Tierra de Campos (1500-1830), Salamanca, Junta de Castilla y León. 